\title{
O curso de graduação em Museologia da ECI/UFMG: concepção e projeto pedagógico
}

\author{
Carlos Alberto Ávila Araújo
}

Professor doutor da Escola de Ciência da Informação da UFMG

Paulo da Terra Caldeira

Professor mestre da Escola de Ciência da Informação da UFMG

Mônica Érichsen Nassif

Professora doutora da Escola de Ciência da Informação da UFMG

Apresenta-se breve histórico da construção do curso de graduação em Museologia da Escola de Ciência da Informação da UFMG. Destaca-se sua vinculação com o programa geral de reestruturação e ampliação dos cursos de graduação da escola, bem como os esforços para integração deste curso aos cursos de Biblioteconomia e Arquivologia. São apresentadas as referências epistemológicas no campo da Museologia e da Ciência da Informação, questões relativas aos museus como instituições e campos de atuação e o espaço da prática profissional em Museologia. Por fim, apresenta-se alguns elementos do projeto pedagógico do curso, que se inicia no ano de 2010.

Palavras-chave: Museologia - ensino; Ciência da Informação - cursos de graduação; Escola de Ciência da Informação da UFMG

\section{The undergraduate course on Museology of Information Science School/UFMG: conception and pedagogical project}

The article shows a brief history of the construction of the undergraduate course on Museology of the Information 
Science School of UFMG. Emphasis is given to the link of the course with the general program of restructuring and amplification of the undergraduate courses of the School as well as the efforts in integrating the new course with the existing Library Studies and Archivology courses. Epistemological references in the field of Museology and Information Science are given and also, questions are raised about museums as institutions and fields and spaces for the professional practice in Museology. Finally, some elements of the pedagogical project of the course (which starts in early 2010) are presented.

Keywords: Museology - teaching; Information Scienceundergraduate courses; Information Science School of UFMG

Recebido em 24.03.2010 Aceito em 20.04.2010

\section{Introdução}

O objetivo do trabalho é apresentar alguns elementos que balisaram a construção do projeto pedagógico do curso de graduação em Museologia da Escola de Ciência da Informação (ECI) da Universidade Federal de Minas Gerais (UFMG). Esse projeto foi construído e aprovado ao longo do ano de 2009, oferecendo 40 vagas no processo vestibular de 2009, com entrada de alunos no segundo semestre de 2010.

Com a conclusão dos trabalhos de planejamento e definição do curso de Museologia, completou-se o processo de estruturação dos cursos de graduação da ECI/UFMG. Esse processo se iniciou há seis anos, com as iniciativas de reestruturação do curso de graduação em Biblioteconomia. Em 2007, sob a influência do REUNI, o Plano de Reestruturação e Expansão das Universidades Federais, lançado pelo Governo Federal, essa proposta de reestruturação passou a ser pensada em conjunto com a necessidade de ampliação da graduação da escola, como forma de adesão ao REUNI. Assim, decidiu-se pela criação dos cursos de graduação em Arquivologia e em Museologia.

Ao longo de 2008, foram elaborados os projetos pedagógicos do novo curso de Biblioteconomia (acrescido da designação "e Gestão da Informação") e do curso de Arquivologia. Esses projetos foram pensados já se tendo em consideração a chegada do curso de Museologia, que seria concebido no ano seguinte, e a ideia de integração entre os três. No final de 2008 foi formalizada a Comissão para Planejamento e Desenvolvimento do Projeto Pedagógico do Curso de Museologia, composta por três professores da ECI: Carlos Alberto Ávila Araújo, Paulo da Terra Caldeira e Mônica Erichsen Nassif. Pouco depois, foi firmada parceria com a Escola de Belas Artes (EBA) da UFMG, que indicou também os seguintes professores para compor a comissão de criação do curso de Museologia: 
Eliana Ribeiro Ambrosio, Marilene Corrêa Maia, Yacy-ara Froner e Willi de Barros Gonçalves. Durante o ano de 2009 foram realizadas várias reuniões, envolvendo também a Rede de Museus e Espaços de Ciências da UFMG, presidida pelo professor Antônio Gilberto Costa, e professores de outras unidades acadêmicas da UFMG, tais como a professora Betânia Gonçalves Figueiredo.

Com a conclusão do processo de criação do curso de Museologia, atingiu-se o objetivo de se construir uma unidade de ensino que se consolide na área de Ciência da Informação, abarcando suas diferentes manifestações, a saber, a Biblioteconomia, a Gestão da Informação, a Arquivologia e a Museologia. Ao mesmo tempo, a construção desse curso se estabelece com o concurso fundamental de parcerias com outras unidades e âmbitos da UFMG, particularmente a Escola de Belas Artes (EBA) e a Rede de Museus e Espaços de Ciências.

\section{Histórico da proposta}

É importante, analisando-se o histórico desse processo, identificar ações específicas que constituem alguns de seus marcos fundamentais. Destacam-se, entre outros, a mudança do nome do Curso de PósGraduação em Biblioteconomia (Administração de Bibliotecas) para Curso de Pós-Graduação em Ciência da Informação, em 1991; a mudança dos nomes dos departamentos da Escola (de Biblioteconomia para Teoria e Gestão da Informação; e de Bibliografia e Documentação para Organização e Tratamento da Informação); a mudança do nome do periódico editado pela escola, de Revista da Escola de Biblioteconomia da UFMG para Perspectivas em Ciência da Informação, em 1996; a mudança do nome da escola, de Escola de Biblioteconomia para Escola de Ciência da Informação, em 2000; e, finalmente, em 2008, a reestruração curricular do curso de Biblioteconomia e, no âmbito do REUNI, a criação do Curso de Graduação em Arquivologia.

As discussões presentes na atual proposta de criação de um curso de Museologia foram antecedidas, portanto, por extenso trabalho voltado para a reformulação do curso de Biblioteconomia e a criação do curso de Arquivologia, tornando possível a criação integrada de mais um novo curso. É importante resgatar a história desse processo, uma vez que, a partir dele, elaborou-se um "tronco comum" de disciplinas e atividades acadêmicas da área de Ciência da Informação, tronco esse que fundamenta e integra os três cursos de graduação da ECI.

A história desse tronco comum remonta ao ano de 2004, quando o Colegiado do Curso de Biblioteconomia da ECI instalou e indicou uma comissão coordenadora formada por nove professores, para dar início às discussões sobre a reestruturação curricular do Curso de Biblioteconomia, com proposta articulada entre as três áreas, ou seja, pensando-se na implantação dos cursos de Arquivologia e Museologia.

As seguintes sub-comissões temáticas foram definidas para discutir as ementas e disciplinas do curso: 
- Fundamentos Teóricos e Metodológicos da Ciência da Informação (FTMCI)

- Princípios Gerais da Organização e Tratamento da Informação (OTI)

- Usuários da Informação (USI)

- Fundamentos Culturais, Políticos e Sociais da Informação (FCPS)

- Gestão da Informação (GI)

- Fontes e Uso da Informação (FUSI)

- Tecnologia da Informação (TI)

Os trabalhos dessa comissão se desenvolveram numa direção, desviada em 2007, a partir das novas condições relativas à expansão da universidade com o Reuni, e tomaram novo rumo. Inicialmente, a proposta consistia na criação de um curso de graduação em Ciência da Informação com habilitações profissionais em Biblioteconomia, Arquivologia e Museologia. Como a meta do Reuni contemplava necessariamente a criação de novos cursos, a ECI optou, então, pela reformulação de um de seus cursos e a criação de outros dois. Nesse processo, a área de Fontes e Uso da Informação acabou por se concentrar em conteúdos do curso de Biblioteconomia, saindo do escopo de atividades obrigatórias do curso de Museologia - permanecendo, contudo, no oferecimento de atividades optativas. As demais seis subcomissões geraram as seis áreas de conhecimento que estruturam o currículo do curso de Museologia.

Com a instituição da parceria com a Escola de Belas Artes (EBA) da UFMG, novas áreas foram incorporadas ao curso, permitindo ao aluno sólida visão dos aspectos da Conservação, além da possibilidade de estudos complementares na área de Teatro, Design gráfico, Ensino da arte, Fotografia e Artes Visuais. Essa nova área foi designada, no projeto pedagógico, como área de Artes e Conservação (AC), constituindo-se portanto na sétima das subáreas de conhecimento presentes no curso de Museologia.

\section{Referências epistemológicas: Museologia e Ciência da Informação}

Bibliotecas, arquivos e museus são instituições cuja origem se confunde com a própria idéia de cultura. Desde as sociedades da Antiguidade, existe a preocupação com a preservação e transmissão das experiências e conhecimentos acumulados, implicando algum tipo de inscrição material destas experiências e conhecimentos. A origem das bibliotecas e arquivos é comumente relacionada à origem da passagem da oralidade para a escrita; a dos museus, associada ao colecionismo que marcou as grandes civilizações da Antiguidade.

A existência dessas instituições levou à criação de uma série de procedimentos e métodos, surgidos diretamente da necessidade de se lidar com seus acervos. Tais procedimentos possuíam caráter eminentemente prático (a resolução de problemas concretos relativos à 
manutenção e atividade dessas instituições), mas a experiência acumulada das técnicas utilizadas ao longo do tempo tendeu a se consolidar como a base das futuras disciplinas científicas. É importante destacar que "durante a Idade Antiga e a Idade Média, museus, arquivos e bibliotecas constituíam praticamente a mesma entidade, pois organizavam e armazenavam todos os tipos de documentos" (ORTEGA, 2004, p. 3). Contudo, o conjunto de técnicas e mesmo o conjunto de questões envolvidas em cada uma delas apresentou, desde o início, pontos de contato mas, também, especificidades próprias. Foi, todavia, no final do século XIX e inicio do século $X X$, sob a égide da formulação do campo de conhecimento da Documentação, com Paul Otlet, que surgiu a idéia de reunificar essas disciplinas no âmbito das assim chamadas "ciências documentais" (PINHEIRO, 2002). A Documentação, como campo de conhecimento, desenvolveu-se nas primeiras décadas do século XX e é usualmente tida como a precursora da Ciência da Informação (BUCKLAND; LIU, 1995; ROBREDO, 2003).

As reflexões sobre o museu começam no século XIX voltadas para as regras de exposição dos acervos propostas por, entre outros, Goethe, em 1821, Ruskin, em 1853, e Bode, em 1903 (FERNÁNDEZ, 1998, p. 18). Logo depois, surgem várias reflexões no campo da arte, havendo aqueles tidos como "defensores" do museu como novo âmbito da arte (como Proust e Malraux, inspirados em Leibniz, Kant e Hegel) e os "detratores" da instituição, que vêem o museu como o fim da arte, entre os quais destacam-se Quincy, Nietzsche, Valèry, Merleau-Ponty e Adorno (HERNÁNDEZ HERNANNDEZ, 1998, p. 67). Desenvolve-se também uma perspectiva historiográfica nos museus, entendidos como "espaços propícios à pesquisa histórica" (JULIÃO, 2006, p. 95), em que os objetos museológicos são tidos como documentos da cultura material, numa linha inaugurada por Le Goff. Nesta perspectiva, a associação entre museu e patrimônio é uma constante, articulando ainda os saberes relacionados com a investigação e a conservação (RIVIĖRE, 1993). Paralelamente a estes dois campos de reflexão, entre 1926 e 1946, a Sociedade das Nações publicou a revista Mouseion e dois volumes de Museographie. E, em 1947, já com o patrocínio da Unesco, foi criado o ICOM, o Comitê Internacional de Museus, que realizou sua primeira reunião em Paris e iniciou a publicação da revista trimestral Museum. Estes dois suportes institucionais foram decisivos impulsionadores da teoria museológica no século XX e que cristalizam "as primeiras definições oficiais de museu" (HERNÁNDEZ HERNÁNDEZ, 1998, p. 69). Mas o grande movimento teórico da Museologia verifica-se na segunda metade do século $X X$, com a "nova museologia" (FERNANDÉZ, 1993, p. 24), proposta por, entre outros, Rivière e Varine (França, criadores do conceito de "ecomuseus"), Gabus (Suíça) e Cameron (Canadá). Tal movimento se institucionaliza por meio da mesa redonda promovida pela Unesco no Chile em 1972 (que começa a discutir a idéia do "museu integral"); da criação do ICOFOM, o Comitê de Museologia do ICOM, em 1977; do I Encontro de Ecomuseus, em Québec, em 1984; e da criação do Minom, o Movimento por uma Nova Museologia, liderado por Pierre Mayrand a partir de um encontro em 
Lisboa, em 1985. O princípio básico da Nova Museologia é o de sair de uma concepção de uma ciência do museu para uma concepção de que tudo pode ser musealizável, isto é, deixar de entender o museu como um fim em si mesmo e entendê-lo como uma das formas possíveis da relação homem/sociedade (HERNÁNDEZ HERNÁNDEZ, 1998, p. 72). Na esteira dos movimentos de descolonização da África, do movimento negro, da descrença nas instituições educacionais e da busca pelos direitos das minorias, os museus deixam de lado a idéia de uma cultura das elites e de fatos excepcionais da história em favor de uma visão das questões da vida cotidiana, concebendo o museu voltado para o público e com função "crítica e transformadora da sociedade" (JULIÃO, 2006, p. 27). Por trás do conceito de "ecomuseu" está a concepção de "valorização das pessoas, dos territórios e do patrimônio cultural", além da busca pela pluralidade estabelecendo pontes entre culturas (NASCIMENTO JR.; CHAGAS, 2006, p. 15)

Já a Ciência da Informação possui suas primeiras definições, na década de 1960 (ROBREDO, 2003; PINHEIRO; LOUREIRO, 1995), tendo como principais características, formuladas nos anos seguintes: sua natureza interdisciplinar (SARACEVIC, 1996; GOMES, 2001), o fato de ela receber das ciências sociais seu traço identificador (GONZÁLEZ DE GÓMEZ, 2000; FROHMANN, 2008) e sua constituição como uma ciência pós-moderna (CARDOSO, 1996; WERSIG, 1993). Ao longo das décadas seguintes, a Ciência da Informação desenvolve-se por meio de diferentes subáreas de pesquisa relacionadas a diversos "programas de pesquisa", a saber: os fluxos da informação científica, a recuperação da informação, a bibliometria, os estudos de usuários, as políticas de informação, a gestão do conhecimento, as possibilidades trazidas com $o$ hipertexto $e$ interconectividade digital (GONZÁLEZ DE GÓMEZ, 2000).

As tendências contemporâneas têm convergido para o entendimento do fenômeno informacional dentro do que Capurro (2003) denominou "paradigma social": a incorporação da dimensão material da informação (enfatizada pelo paradigma físico, iniciado na década de 1960) e de seus aspectos cognitivos (a relação entre informação e conhecimento, ou entre suas manifestações explícitas e tácitas, conforme entendido pelo paradigma cognitivo, em vigor desde o final da década de 1970) a um entendimento de informação como definida intersubjetivamente, vinculada a contextos sócio-históricos concretos que a determinam. As discussões mais recentes do campo têm evoluído na confluência dessa compreensão. É o caso da abordagem conhecida como "análise de domínio", que enfatiza a importância do estudo das comunidades discursivas que se relacionam com a informação, isto é, ao caráter pragmático daquilo que é definido como informação, sempre em função dos interesses e atividades de determinados grupos (HJORLAND, 2002). Também é o caso dos estudos que enfatizam a dimensão hermenêutica que se relaciona com o fenômeno, isto é, da ênfase nos processos de produção de sentidos e significados com/a partir da informação (CAPURRO; HJORLAND, 2003; CORNELIUS, 2002). Nessa mesma linha, a informação vem sendo entendida como algo que tem origem em dados, objetos sensíveis, mas 
que é algo muito além disso, só se realizando como fenômeno a partir da intervenção dos sujeitos - ou seja, a informação não surge como ente acabado e autônomo - é, antes, construída na perspectiva dos sujeitos e interrelacionada com o campo da cultura (RENDÓN ROJAS, 2005). Assim, também muitos estudos têm ressaltado a vinculação das práticas informacionais com as dimensões sociais, políticas, econômicas e culturais, por meio de sua materialidade, mas não restrita a ela (FROHMANN, 2008).

As tentativas de integração entre essa Ciência da Informação e os campos teórico e profissional da Biblioteconomia, da Arquivologia e da Museologia ganharam fôlego com as iniciativas da Unesco nas décadas de 1960 e 1970 de amplos programas no âmbito de ações culturais, vinculando as questões de memória, patrimônio e políticas culturais sob a idéia do documento e da informação registrada. A proposta, naquele momento, era integrar os diferentes saberes de forma a se superar a ideia de produção de conhecimentos e atuação profissional necessariamente vinculados a uma instituição específica (as bibliotecas, os arquivos e os museus).

No Brasil, os momentos mais importantes de aproximação dessas disciplinas se deram em 1998, quando a Secretaria de Educação Superior do Ministério da Educação e do Desporto (SESu/MEC) designou uma Comissão de Especialistas de Ensino de Ciência da Informação, com a incumbência de elaborar diretrizes curriculares para os cursos de Arquivologia, Biblioteconomia e Museologia a serem ministrados no país; em 2002, quando da realização do primeiro "Integrar - Congresso Internacional de Arquivos, Bibliotecas, Centros de Documentação e Museus", em São Paulo; e em 2006, quando da realização do II Integrar, também em São Paulo. No ano seguinte, em Salvador, o Enancib, Encontro Nacional de Pesquisa em Ciência da Informação, reservou a estrutura de um Grupo de Trabalho específico para a discussão da Museologia. Contudo, é importante perceber como se constituíram, historicamente, as características destas áreas como campos de conhecimento. Conforme aponta Silva (2006), tanto a Museologia quanto a Biblioteconomia e a Arquivologia têm origem, como campo de conhecimento científico nos moldes da ciência moderna, no século XIX, e se constituem, como tais, a partir de um paradigma patrimonialista, caracterizado pela:

a) visão historicista, empírico-tecnicista, documentalista, empíricopatrimonialista;

b) sobrevalorização da custódia, guarda, conservação e restauro;

c) ênfase na idéia da memória como fonte legitimadora do EstadoNação moderno;

d) distinção formal e profissional das três áreas, mas reconhecendo que todas conservam, preservam, coligem, ordenam, classificam e difundem documentação.

Este mesmo autor identifica que, ao longo do século $X X$, tal paradigma deu lugar a outro, em torno da "noção operatória de informação", impulsionado por, entre outros fatores, as inovações 
tecnológicas. Nesse movimento, passaram a se constituir como características destes campos:

a) a valorização da informação;

b) o dinamismo informacional em oposição ao imobilismo documental;

c) os modelos teórico/científicos em oposição a um conjunto uniforme e acrítico de modos/regras de fazer.

O autor defende, assim, a idéia de que as três áreas "fazem parte integrante de um corpus científico unificado pelo mesmo objeto" (SILVA, 2006, p. 590) e que esse objeto seria a informação, enquanto fenômeno e enquanto processo.

A idéia de integração entre as três áreas é também defendida por Smit (2002), autora que levanta uma série de questões para argumentar que, apesar de diferenciados institucional e profissionalmente, as três áreas contribuem de forma complementar para a disponibilização da informação estocada dentro de objetivos comuns. Para ela, existe uma tradição de separação, em que suas semelhanças são sistematicamente ignoradas, originada por um embate entre duas visões: uma, calcada nas práticas profissionais, ancorada no paradigma do acervo, e outra, voltada para a função social de instituições que coletam, estocam e disponibilizam informações. Para ela, 0 isolacionismo constitui um fator de empobrecimento do campo. Contudo, constata Smit, as três áreas não nasceram separadas - elas se afastaram ao longo do tempo. O que as une, na visão da autora, é o fato de serem "ciências documentais".

Entre os fatores contemporâneos que marcam a reaproximação entre elas, destacam-se: a utilização cada vez mais acentuada das tecnologias digitais e a mudança da ênfase do acervo para o usuário. Com isso, haveria três fortes pontos de união: a gestão da memória (seleção, coleta, avaliação de documentos); a produção de informação documentária (representação da informação estocada, bases de dados, catálogos, resumos); e a mediação da informação (comunicação das informações, transferência, atendimento das necessidades dos usuários). Conclui Smit: "Desenha-se, neste momento, uma acepção possível para a CI enquanto disciplina científica (...) o estatuto científico da área somente poderá ser confirmado quando for abandonada a visão pragmática das práticas profissionais e quando se dispuser de teorias e princípios gerais, comuns às três (...)" (2002, p. 34).

Mesmo no âmbito de estudos voltados de maneira específica para o fazer museológico, é comum a associação entre Museologia e Ciência da Informação, como no exemplo a seguir: "Partindo-se do pressuposto de que objetos/documentos são suportes de informação, o grande desafio de um museu é preservar o objeto e a possibilidade de informação que ele contém e que o qualifica como documento" (CÂNDIDO, 2006, p. 34). Ou ainda: "O processo de fornecer informações a partir dos dados existentes é da área comum dos profissionais das chamadas ciências documentais. Arquivos, bibliotecas, centros de documentação e museus são coresponsáveis no processo de recuperação da informação" (CÂNDIDO, 2006, p. 36). 
A respeito da Ciência da Informação, deve-se ressaltar que já suas primeiras definições (Borko, 1968) enfatizavam a necessidade de desenvolvimento de um aporte científico aos processos pelos quais normalmente são submetidos os produtos informacionais, a saber: a coleta, a catalogação, a classificação, o armazenamento, a disseminação, a transferência e o uso, entre outros.

Ao longo dos anos, novas questões e aspectos passam a se incorporar ao campo, tais como: os vínculos entre os conhecimentos produzidos, o desenvolvimento tecnológico e a consolidação de uma "sociedade da informação" (SARACEVIC, 1996); o reconhecimento da importância central do usuário da informação, recolocando as dimensões social e cultural no centro das preocupações do campo (CARDOSO, 1996); o deslocamento do âmbito de preocupação do espaço específico das instituições de informação (bibliotecas, arquivos, museus) para um alargamento que considera os fluxos e usos em diferentes contextos e realidades (MIKSA, 1992).

Com vertentes que se traduzem em diferentes linhas de pensamento e pesquisas, a Ciência da Informação foi assumindo, ao longo dos anos, caracterizações distintas, como uma ciência fortemente marcada pela idéia de interdisciplinaridade, como uma ciência social e ainda, conforme a discussão específica de alguns autores, como uma ciência pertencente ao movimento de constituição das ciências ditas pósmodernas.

A literatura especializada mostra que observou-se, por muito tempo, um isolamento entre a Museologia, a Biblioteconomia e a Arquivologia, com grande ímpeto de defesa de espaços e competências, mas que, na atualidade, o cenário científico acena para a busca da integração, tendo por alicerce 0 novo modelo da interdisciplinaridade $e$ do compartilhamento.

Frente a esse panorama, a ECI/UFMG propõe um curso que integra os três campos, tendo a Ciência da Informação como estrutura básica da formação desses profissionais da informação, com o oferecimento de ramificações que possibilitem a formação especializada nos cursos de Museologia, Biblioteconomia e Arquivologia. Além de um forte aporte em Conservação, através da disciplinas ministradas na Escola de Belas Artes que nos últimos 30 anos tem se ocupado de formar ConservadoresRestauradores através de seu Centro de Conservação-Restauração de Bens Culturais Móveis (CECOR).

\section{Museus como instituição e campo de atuação}

O ICOM conceitua o museu como uma "instituição permanente, sem fins lucrativos, a serviço da sociedade e de seu desenvolvimento, aberta ao público, que adquire, conserva, pesquisa, divulga e expõe, para fins de estudo, educação e lazer, testemunhos materiais e imateriais dos povos e seu ambiente" (PEREIRA et al, 2007, p. 11). Além de todas essas atividades Pereira et al consideram também que "os museus são ambientes culturais e educativos" que "pretendem educar por meio da 
sensibilização e cultivam a comunicação e produção de significados a partir de seus objetos, exposições, propostas educativas". Estão embutidos em tais conceitos que os museus são instituições "de memória das sociedades, das nações, dos grupos, das comunidades [...] detentores de coleções, de indícios patrimoniais e identitários". São, portanto, instituições sociais, culturais e históricas, promotaras de argumentos culturais, políticos e éticos, vinculando-se a uma temporalidade e às peculiaridades de uma sociedade.

O termo museu (CALDEIRA, 2008, p. 393-394), do latim museum, tem sua origem nas palavras gregas mousa (templo e morada das musas, lugar consagrado às nove musas) e mouseion, que designava a parte do palácio de Ptolomeu I (c. 367/366-283/282 a.C.), em Alexandria, Egito, onde sábios e filósofos se reuniam para estudar as ciências, as letras e as artes. O local, constituído de biblioteca, salão de leitura, jardim botânico, zoológico, observatório é considerado como o primeiro museu.

O interesse em colecionar objetos de arte, "paixão anárquica e destrutiva" que tem a intenção de preservar recortando "a tradição e destruindo o contexto do qual o objeto fizera parte" (COLECIONISMO, 2002, p. 20), remonta à época helenística, quando os gregos amealhavam materiais preciosos, raros exóticos. Os templos da Grécia antiga continham, em suas fachadas e dependências, estátuas, vasos, pinturas, peças em ouro, prata e bronze, expostos à admiração pública. Esse gosto por obras de arte foi continuado pelos romanos e, no final da República e do Império, são formadas coleções de objetos obtidos durante as guerras, com a pilhagem de peças que, posteriormente, eram exibidas e apreciadas pelos cidadãos, durante os ofícios religiosos, em procissões, em acontecimentos políticos, nos templos, fóruns, teatros, saunas e jardins públicos.

Sob outro olhar, a construção de suntuoso templo feita pelo Imperador Publius Aelius Hadrianus (76-138) em sua vila em Tívoli, Itália, para lembrar os locais favoritos que visitara no Egito e na Grécia, pode ser considerada como a precursora dos atuais museus ao ar livre. Nela se podiam observar os

"tesouros do mundo exterior trazidos para o interior da residência, convertida em lugar que representa e permite contemplar o universo". Colecionar é, pois, "ato de paixão, movido por impulsos psíquicos; forma de estabelecer um domínio sobre o mundo, organizando-o sistematicamente; tensão permanente entre ordem e desordem, preservação e destruição; flâniere entre tesouros do mundo apropriados pelo homem privado; estabelecimento de comunicação com aquilo que está ausente, conferindo existência e permanência à relação entre o homem e o mundo invisível." (COLECIONISMO... 2002, p. 20).

É a partir desse contexto que, no séc. XIV desenvolveram-se entre os senhores feudais esses impulsos ou hábito de colecionar objetos, não 
tanto pelo seu valor pecuniário, mas pelo que eles representavam em termos científicos e culturais. Reunir obras de arte tornou-se uma questão de prestígio para os grandes senhores, e, da mesma forma, também a Igreja Católica, ao exibir esculturas, murais, mosaicos, vitrais e tapeçarias, com a finalidade de cativar seus fieis. Portanto, na Idade Média, igrejas, conventos e mosteiros europeus transformaram-se em verdadeiros museus, ao abrigarem imagens, estátuas, pinturas, pratarias, manuscritos, jóias e relíquias de toda espécie.

No Renascimento, pode-se constatar que os palácios dos príncipes, nobres, autoridades eclesiásticas e famílias italianas notáveis e abastadas abrigavam importantes coleções de obras de arte. É conseqüência desse cenário que, na segunda metade do séc. XV o termo museu passa a ser usado para designar uma coleção de objetos considerados belos e valorizados comercialmente.

A criação dos museus modernos toma impulso com as doações de coleções particulares que passaram ao domínio público e coleções reais são abertas à visitação pública, culminando com a ampliação do acesso a esses acervos, como foi o caso do governo francês, que autorizou o acesso ao público, ao palácio Luxemburgo, em Paris, que abrigava o acervo do Rei Francisco I (1494-1547) cuja coleção foi transferida, em 1773, para o edifício denominado Louvre. É, portanto, a partir dessa consciência social de disponibilização de tais preciosidades que são criados os grandes museus europeus, no final do séc. XVIII como os museus do Vaticano, em Roma: O Sacro (1756) e o Pio Clementino (1770-1774); o Museu Nacional de Ciência (1771) e o Museu do Prado (1783), ambos em Madrid; o Museu Real dos Países Baixos, em Amsterdam (1808); o Altes (1810), em Berlim; o dos Artistas Vivos (1818), em Paris; o de Versailles (1833); o Hermitage (1852), em São Petersburgo; o Belvedere (1873), em Viena; o Prado (1919), em Madri. Nos Estados Unidos, destacam-se o American Museum of Natural History (1869) e o Metropolitan Museum of Art (1870), em Nova Iorque.

No Brasil, Dom João VI criou dois importantes museus: o primeiro, em 1816, por meio de doação dos quadros adquiridos na Europa por Joachim Lebreton, chefe da Missão Francesa de Artistas e Artífices, à Escola Real das Ciências, Artes e Ofícios do Rio de Janeiro. Esse acervo foi repassado, posteriormente, à Escola Nacional de Belas Artes até 1937, quando da criação do Museu Nacional de Belas Artes. O segundo, em 1818, foi o Museu Real, instalado no prédio do atual Arquivo Nacional, até 1892, quando foi transferido para o Palácio de São Cristóvão, na Quinta da Boa Vista, na mesma cidade.

No séc. XXI, os mineiros foram agraciados com dois museus: o Inhotim, em Brumadinho, inaugurado em 2005 com pavilhões espalhados entre montanhas, lagos e um paisagismo exuberante, unindo natureza, animais, plantas, homens e obras de arte, em um conjunto amplo e harmonioso. O segundo é o Museu Inimá (2008), em Belo Horizonte, com obras do grande artista fauvista, nascido em Itanhomi, em 1918.

Sobre a importância dos museus, Pereira et al (2007, p. 11) afirmam que "os museus são ambientes culturais e educativos" que 
"pretendem educar por meio da sensibilização e cultivam a comunicação e produção de significados a partir de seus objetos, exposições, propostas educativas..." Assim, para atingir tais objetivos realizam exposições utilizando como meio de comunicação com o publico, a palavra, que procurará dar sentido ao objeto ou à exposição como um todo.

Castro (2007, p. 105) pondera que, dentre as

"instituições de memória, o museu tem um papel impar na sociedade moderna como mediador entre o público e o acervo, e enquanto o comunicador e produtor do discurso. A forma pela qual o público recebe o conteúdo e a mensagem de uma exposição museológica assegura e garante a legitimidade" de sua função social.

A exposição em um museu consiste na "exibição de objetos organizados e dispostos com o objetivo de comunicar um conceito ou uma interpretação da realidade. Pode ser de caráter permanente, temporário ou itinerante. Meneses, (2005, p. 30) afirma que "a primeira orientação de uma exposição deveria ter como meta a alfabetização museológica " e Caston acrescenta que a função educacional do museu só será completa se ele ensinar o que é um museu, uma exposição e como devem e podem ser usados, o que não significa que toda exposição deverá contar com colaboração de monitores.

Rússio, citada por Cândido (2006, p.35) afirma que "a museologia tem por matéria de estudo a relação entre homem/sujeito e objeto/bem cultural, num espaço cultural denominado museu", e que o conceito de documento "surge a partir da relação que se pode manter com 0 documento/testemunho". Entretanto, os objetos se tornam documentos quando

"interrogados de diversas formas, e todos os objetos produzidos pelo homem apresentam informações intrínsecas e extrínsecas a serem identificadas. Informações intrínsecas são deduzidas do próprio objeto, a partir da descrição e análise das suas propriedades físicas (discurso do objeto); as extrínsecas, denominadas de informações de natureza documental e contextual, são aquelas obtidas de outras fontes que não o objeto (discurso sobre o objeto)" (CANDIDO, 2006, p. 35).

Ainda segundo a autora, "a Museologia, concebida e considerada antes como uma técnica de preservar, classificar, organizar e expor objetos culturais e naturais" vem sendo reconhecida como disciplina científica e os profissionais esforçam-se em elaborar uma teoria para a área.

"O sistema de documentação museológica das atividades de um museu deve considerar seus objetivos (conservar os itens da coleção, maximizar o acesso e o uso das informações nele contidas), sua função (estabelecer contatos efetivos entre as 
fontes de informações: itens, e os usuários: transmissão e apropriação de conhecimento), e seus componentes (entradas: seleção, aquisição; organização e controle: registro; número de identificação/marcação; Armazenagem/localização; classificação/catalogação; indexação)".

Uma questão importante na caracterização da instituição museal diz respeito à sua tipologia. Figueiredo (2005, p.21) afirma que todos os museus são históricos podendo operar tanto as dimensões de espaço como de tempo (Musée dês Monuments Français, 1795 e Musée de Cluny, ambos em Paris. No século XIX o desenvolvimento dos museus históricos está associado ao surgimento das nacionalidades, nos quais ressalta-se a importância dos museus de arqueologia. Nos Estados Unidos "educação popular e pesquisa acadêmica são os eixos que ajudam a modelar os museus de história natural" apontando para a tecnologia, como traço distintivo da nação independente que se procura afirmar. O Brasil segue o modelo oitocentista de museu de História Natural, nele compreendido a Antropologia e a História. Apenas nos anos de 1920 é o que o Museu de História passa a ser uma categoria distinta das demais.

Desta forma a autora considera que o objeto, isolado ou agrupado, e sua natureza determinarão a tipologia do museu. Assim pode-se encontrar a seguinte tipologia:

a) Museus enciclopédicos - observa-se uma variedade de assuntos e objetos expostos. São exemplos: British Museum, Londres; Metropolitan Museum, Nova Iorque;

b) Museus de dedicados a uma ou mais áreas do conhecimento têm por função identificar e adquirir o acervo, divulgar e estimular seu estudo pelos pesquisadores e sua apreciação pelo público em geral. São eles:

b.1) Museus históricos - as coleções são concebidas e apresentadas sob uma perspectiva histórica tendo como função relembrar o passado e comprovar fatos das história das nações. Destacam-se: Museu Histórico Nacional, Rio de Janeiro, 1922; Museu Imperial, 1940, Petrópolis; Museu Histórico Abílio Barreto, 1943, Belo Horizonte; Museu da Inconfidência, 1944, Ouro Preto, MG; Museu da República, 1960; Museu do Primeiro Reinado, 1979, os dois últimos no Rio de Janeiro;

b.2) Museus de Arte - a concepção e disposição das coleções são apresentadas conforme o valor estético de cada peça. Subdividem-se em museus de arte sacra, de pintura, de escultura, de artes decorativas, primitivas, aplicadas, industriais, antiguidades, folclore. Ressaltam-se: Tate Gallery e Modern Tate, Londres; Museum of Modern Art, New York; Museu Nacional de Belas Artes, Rio de Janeiro, 1937; Museu de Arte Moderna, Rio de Janeiro; Museu de Arte de São Paulo Assis 
Chateaubriand, 1947, São Paulo; Museu Víctor Meireles, 1952, Florianópolis; Museu de Arte Contemporânea, 1963, São Paulo; Museu de Arte Sacra, 1969, São Paulo; Museu Regional Casa dos Otoni, 1976, Serro, MG; Museu de Arte Contemporânea de Niterói, 1993, Niterói.

Ainda na tipologia de museus de arte é importante salientar as subdivisões:

b.2.1) Museus de Arte Sacra: Museu Mineiro, 1910, Belo Horizonte; Museu Arquidiocesano de Arte Sacra de Mariana, 1962, Mariana; Museu de Arte Sacra de São Paulo, 1969, São Paulo; Museu de Arte Sacra de Pernambuco, 1977, Olinda, PE; Museu de Arte Sacra de Ouro Preto/Paróquia do Pilar, 1987, Ouro Preto;

b.2.2) Museus de Artes decorativas: Museu Carlos Costa Pinto, 1969, Salvador; Museu do Açude, 1963, Rio de Janeiro;

b.2.3) Museus de arte primitiva: Museu Internacional de Arte Naïf do Brasil, 1985, Rio de Janeiro;

b.3) Museus de Folclore: Museu de Folclore Edison Carneiro, 1969, Rio de Janeiro;

b.4) Museus de Arqueologia, de Antropologia, de História Natural, de Zoologia, de Botânica, de Geologia: Museu Etnográfico de São Petersburgo, 1836, National Museum, 1837, Leiden; Museu Parense Emílio Goeldi, 1866, Belém; Museu Oceanógrafo, 1978, Imbé, RS; Museu de Paleontologia de Monte Alto, 1992, Monte Alto, SP;

b.5) Museus de Ciência - preocupam-se com o meio ambiente, o aperfeiçoamento científico e cultural da comunidade, os avanços tecnológicos: Museu Paulista ou Museu Ypiranga, 1894; Museu de História Natural e Jardim Botânico da UFMG, 1968, Belo Horizonte; Museu Nacional do Rio de Janeiro, 1808, Estação Ciência, 1987, USP, São Paulo; Museu de Astronomia, Rio de Janeiro; Casa da Ciência, UFRJ, Rio de Janeiro; Espaço Museu da Vida, Fiocruz, Rio de Janeiro; Espaço Ciência, SECT, PE, Museu de Ciências Naturais, 1983, PUC-MG, Belo Horizonte; Museu de Astronomia e Ciências Afins, 1985, Rio de Janeiro; Parque da Ciência, ES;

b.6) Museus de Tecnologia - surgiram com o propósito de mostrar os avanços científicos para estudantes e a população em geral: Museu de Ciência e Tecnologia, MCT/PUC, RS; Museu Contemporânea das Invenções, 1996, São Paulo;

c) Museus Temáticos/Regionais: Museu do Ouro, 1945, Sabará, MG; Museu do Diamante e Biblioteca Antônio Torres, 1954, Diamantina, MG; Museu da imigração e Colonização, Joinville, SC; Museu de Arqueologia e 
Artes Populares, Paranaguá, PR; Museu das Missões, Santo Ângelo, RS; Museu do estanho, 1986, São João del Rei;

d) Museus Micro-temáticos - ou a respeito de determinados objetos: prataria, porcelana, telefone, etc.: Museu do Eucalipto, 1916, Rio Claro, SP; Museu da Pesca, 1930, Santos, SP; Museu do Telefone, 1976, Bragança Paulista; Museu do Bordado, Belo Horizonte, MG; Museu do Crime, 1930, São Paulo; Museu de Numismática, 1900, Manaus; Museu dos Ex-Votos do Senhor do Bonfim, 1975, Salvador; Museu da Porcelana Sr. Adelino dos Santos Gouveia, 1995, Pedreira, SP; Museu da Motocicleta (Moto Museu século XX), 1996, Fortaleza; Museu do Automóvel, 1981, Fortaleza; Museu do Trem, 1984, Rio de Janeiro; Museu do couro, 1984, Campo Maior, PI; Museu do Vinho, 1985, Videira, SC; Museu da Loucura, 1996, Barbacena; Museu do Botão, Curitiba; Museu do Mamulengo. Espaço Tiridá, 1994, Olinda.

e) Ecomuseus - o advento dos parques nacionais e dos museus a céu aberto, a partir de 1850 apontavam para o museu situado

"além dos espaços construídos e dos conjuntos de objetos, desvelando a possibilidade da sua existência sob a forma de áreas naturais que, em conseqüência da evolução dos paradigmas científicos e da revalorização das teorias 'holísticas', configura-se outro modelo de Museu: o Museu Integral - espaço ou território musealizado, no qual sociedade, memória e produção cultural formam um todo indissolúvel..." (SCHNEINER, 2008, p. 41).

no qual "a base conceitual não é o objeto, mas o território do Homem, com suas características geográficas, ambientais e de ocupação e produção cultural". Ainda para a autora, "a percepção do Museu como fenômeno ou manifestação cultural, capaz de assumir diferentes formas e apresentar-se de diferentes maneiras, de acordo com os sistema de valores priorizados em cada sociedade, configura bases de análise específicas da Museologia" não abordadas em outras áreas.

Scheiner (2008) afirma também que os fundamentos teóricos da museologia incluem o caráter plural do Museu: diferentes forma de representação, que podem coexistir no tempo e no espaço; percepção de que é processo, e não produto cultural; compreensão da liberdade de espaço, fato, fenômeno ou objeto; estudo dos processos intrínsecos a ele relacionados e que têm como base o processo de musealização, sobre o qual se constituem os processos curatoriais.

"Assim como na educação, o processo museológico é compreendido como ação que se transforma, resultado de ação e reflexão dos sujeitos sociais, em determinado contexto, passível de ser repensado, modificado e adaptado, contribuindo para a construção e reconstrução do mundo. 
Daí, o sentido de 'associar-se' o termo processo às ações de musealização, compreendido como uma seqüência de estados de um sistema que se transforma, por meio do questionamento reconstrutivo, e que, ao transformar-se, transforma o sujeito e o mundo. A utilização do termo processo permite atribuir, portanto, as dimensões social e educativa à Museologia" (SANTOS, 2002, p. 314).

Os museus geralmente são mantidos pelo poder público ou fundações, podendo-se classificá-los inicialmente como museus públicos e museus privados ou estarem ligados ou patrocinados por empresas particulares.

O papel social dos museus manifesta-se no estímulo à participação da comunidade em suas programações e na divulgação da cultura entre os diversos segmentos da população, por meio da contemplação das peças expostas; expressam as necessidades educacionais e culturais da sociedade contemporânea, constituindo-se em instrumentos para atendêla em suas pretensões, por intermédio da freqüência de seus cidadãos, estudiosos e viajantes que a eles acorrem para satisfazer seus anseios culturais e intelectuais.

Os museus evidenciam, por meio de suas coleções, o que concerne à história natural, à arqueologia, à etnologia, à antropologia, á arte, apresentando indícios de sociedades primitivas, patrimônios permanentes e naturais, novas invenções e descobertas, desvelando-as para os visitantes como um legado para a preservação da história, da biologia, da moral, da religião, da cultura e da estética.

Ação educativa são procedimentos que promovem a educação no museu, tendo o acervo como centro de suas atividades podendo estar voltada para a transmissão do conhecimento dogmático, resultando em doutrinação e domesticação, ou para a participação, reflexão crítica e transformação da realidade social. Neste caso, deve ser entendida como uma ação cultural, que consiste no processo de mediação, permitindo ao homem apreender, em um sentido amplo, o bem cultural, com vistas ao desenvolvimento de uma consciência crítica e abrangente da realidade que 0 cerca. Seus resultados devem assegurar a ampliação das possibilidades de expressão dos indivíduos e grupos nas diferentes esferas da vida social. Concebida dessa maneira, a ação educativa nos museus promove sempre benefício para a sociedade, em última instância, o papel social dos museus.

Entre as atividades educacionais desenvolvidas destacam-se a pesquisa e a divulgação do acervo, conduzidas por meio do estudo de peças da coleção de reserva e de exposições permanentes, além de mostras especiais, dirigidas a estudante, entre outros. Mantêm ainda programas sistemáticos de visitas guiadas, além de cursos para professores e educadores que lhes possibilitem desenvolver técnicas de ensino utilizando o estudo de coleções museológicas, criando situações lúdicas e reflexivas frente às obras, procurando questioná-las e compreendê-las, de modo que sejam assimiladas e relacionadas com o cotidiano (MAGALHÃES, 1982, p. 10). 
Nos últimos anos, o governo brasileiro vem procurando estabelecer políticas para seus Museus. O Ministério da Cultura e o Instituto do Patrimônio Histórico e Artístico Nacional vêm estimulando a criação da Política Nacional de Museus, a criação do Departamento de Museus e Centros Culturais do Instituto do Patrimônio Histórico e Artístico Nacional e também investindo recursos públicos em alguns museus nacionais.

É também do Ministério da Cultura e do IPHAN o criação do Sistema Brasileiro de Museus, iniciativa que pretende promover a articulação e o desenvolvimento dos museus brasileiros, $e$ incorporando os museus estaduais e municipais.

\section{Museologia como campo de atuação profissional}

O curso de Museologia vem atender a interesses e expectativas relacionadas com o mercado de trabalho, as políticas e legislações nacional e estadual de museus, a necessidade de qualificação dos atuais profissionais atuantes no campo e o impacto causado pela utilização das tecnologias digitais.

A área de conhecimento e atuação da Museologia se encontra institucionalizada em um estágio de desenvolvimento social e político que poderia ser considerado mediano no país. Existe legislação federal norteadora das atividades museológicas, em órgãos públicos e privados, assim como entidades públicas voltadas para a criação e a gestão de museus em níveis federal e estadual.

A legislação que dispõe sobre a regulamentação a profissão do Museólogo é a LEI N 7.287, de 18 de dezembro de 1984. Já o Decreto No 91.775 , de 15 de outubro de 1985, regulamenta a Lei no 7.287, de 18 de dezembro de 1984, que dispõe sobre a profissão de Museólogo e autoriza a criação do Conselho Federal e dos Conselhos Regionais de Museologia. Outra referência legislativa importante é o Decreto $\mathrm{n}^{\circ} 5.264$, de 05 de novembro de 2004, que cria o Sistema Brasileiro de Museus - SBM.

O Cadastro Nacional de Museus, feito pelo Sistema Brasileiro de Museus do Ministério da Cultura, registra a presença de 2600 museus presenciais no país, dos quais 2410 são instituições abertas ao público, 78 são instituições em implantação e 112 são instituições fechadas. Há ainda o registro de 18 museus virtuais - totalizando 2618 museus mapeados ${ }^{1}$.

Pelo fato de ser uma carreira pouco conhecida, as funções de um museólogo acabam sendo exercidas por outros profissionais, como os historiadores, arquitetos, sociólogos. O universo de trabalho técnico do museólogo corresponde às funções básicas dos museus: aquisição, documentação, pesquisa, interlocução com o conservador-restaurador, comunicação e exposição de bens culturais. O mercado de trabalho para um museólogo engloba as áreas técnica (atuação em museus, bibliotecas, arquivos e centros culturais, além de órgãos do patrimônio histórico, artístico e cultural), docente (magistério em instituições de educação

\footnotetext{
${ }^{1}$ Informação disponível em: http://www.museus.gov.br/cnm estatistica.htm. Acesso em: 27 de março de 2009.
} 
básica e média) e de prestação da serviços (em empresas especializadas na prestação desse tipo de serviço).

O museólogo, contudo, não tem seu campo restrito às instituições museais. A noção de bem cultural é bem mais ampla do que pode parecer, uma vez que a museologia sintoniza-se com o conceito de patrimônio integral, cultural e natural. A possibilidade de atuar na musealização de bens culturais (processos, fenômenos e objetos) amplia as possibilidades de atuação desse profissional, desde os museus de história e de arte, passando pelos museus arqueológicos e etnográficos, museus de ciências e de tecnologias, ecomuseus e museus comunitários, museus universitários, museus militares, fundações culturais, programas de memória e patrimônio, centros de pesquisa e documentação, centros de conservação e restauração, sítios arqueológicos e históricos, cidadesmonumento, planetários, secretarias e outros órgãos públicos de cultura e patrimônio, arquivos e bibliotecas, antiquários e galerias de arte, teatros e redes de televisão, coleções públicas e particulares.

O profissional também pode realizar pesquisa (para televisão, teatro e cinema), prestar consultoria organizacional (coordenação de exposições nacionais e internacionais, organização de eventos e produção cultural) e turística (atividades relacionadas ao turismo ecológico, cultural e educativo). Além disso, cada dia mais o profissional da museologia utiliza, no seu dia-a-dia, a informática e as novas tecnologias para auxiliá-lo em quase todas as suas funções. A organização do acervo, com a ajuda da tecnologia digital, é muito mais eficiente. Além disso, a evolução das técnicas de conservação e restauração faz com que esse campo seja muito procurado.

A maior expectativa no mercado de trabalho para museólogos gira em torno da criação do Sistema Nacional de Museus, aprovado em 2004 pelo governo federal. A proposta do novo sistema é incentivar a implantação de novos museus no país e a melhoria dos serviços prestados pelos que já estão em funcionamento, abrindo novas vagas de emprego para os profissionais da área.

A forte tendência de investimentos das empresas privadas em centros culturais também incrementou o mercado de trabalho para 0 museólogo - assim como a valorização da cultura nacional tem incentivado a criação de museus, inclusive pelas cidades do interior. No entanto, mesmo com o aumento dos postos de trabalho fixo, a maioria das oportunidades são para profissionais liberais, contratados para a catalogação e conservação de acervos particulares, organização de exposições e classificação de coleções.

\section{Proposta conceitual do curso}

O Curso de Museologia tem por objetivo formar bacharéis em Museologia, tal como enfatizado. O objeto de estudo do curso se encontra delineado nas disciplinas e atividades acadêmicas, em consonância com as bases epistemológicas da área. Esforços serão empreendidos no sentido de se criar novas linhas de pesquisa na ECI, visando estimular pesquisas e 
estudos avançados que subsidiem novos conhecimentos para o campo, e, além disso, possibilitem a formação de professores e pessoal de alto nível, para atuar no mercado, na gerência de redes e sistemas de museus que exijam uma maior complexidade.

Os museólogos devem ter domínio dos conteúdos da museologia e estarem preparados para enfrentar, com proficiência e criatividade, os problemas da sua prática profissional, particularmente as que demandam intervenções em museus, centros de documentação ou informação, centros culturais, serviços ou redes de informações, órgãos de gestão do patrimônio cultural.

Nas Diretrizes Curriculares para a área, originadas do MEC/Conselho Nacional de Educação (CNE), enumeram-se dentre as competências e habilidades dos graduados em Museologia, as de caráter geral e comum, típicas desse nível de formação e aquelas de caráter específico.

Gerais:

- Identificar as fronteiras que demarcam o respectivo campo de conhecimento;

- Integrar conteúdos de áreas correlatas;

- Utilizar as metalinguagens pertinentes;

- Articular elementos empíricos e conceituais com propriedade;

- Gerar produtos resultantes dos conhecimentos adquiridos;

- Desenvolver e aplicar instrumentos de trabalho adequados;

- Formular e executar políticas institucionais;

- Elaborar, coordenar, executar e avaliar planos, programas e projetos;

- Utilizar racionalmente os recursos disponíveis;

- Desenvolver e utilizar novas Tecnologias;

- Traduzir as necessidades de indivíduos, grupos e comunidades nas respectivas áreas de atuação;

- Realizar ações pedagógicas voltadas para a melhoria do desempenho profissional e para a ampliação do conhecimento na área;

- Desenvolver atividades profissionais autônomas, de modo a orientar, dirigir, assessorar, prestar consultoria, realizar perícias e emitir laudos técnicos e pareceres;

- Responder a demandas determinadas pelas transformações que caracterizam o mundo contemporâneo.

Específicas:

- Compreender o Museu como fenômeno que se expressa sob diferentes formas, consoante sistemas de pensamento e códigos sociais;

- Interpretar as relações entre homem, cultura e natureza, no contexto temporal e espacial;

- Intervir, de forma responsável, nos processos de identificação, musealização, preservação e uso do patrimônio, entendido 
como representação da atividade humana no tempo e no espaço;

- Realizar operações de registro, classificação, catalogação e inventário do patrimônio natural e cultural;

- Planejar e desenvolver exposições e programas educativos e culturais.

O Curso de Bacharelado em Museologia tem como fundamentação pedagógica o oferecimento de disciplinas teóricas e práticas, obrigatórias e optativas, e também as opções de formação complementar e formação livre, previstas no projeto de flexibilização curricular da UFMG. Tem como objetivo fazer com que o aluno seja co-responsável pela construção de seu currículo, conquistando, não somente uma formação teórico-prática generalizada, mas também uma especialização em áreas de seu maior interesse pessoal.

As disciplinas disponibilizadas pelo Curso de Museologia terão também como objetivo mostrar em que área os futuros profissionais poderão atuar e suas características próprias, assim como os recursos disponibilizados pelas novas tecnologias e sua utilização nas diversas áreas da profissão, sempre em atendimento aos interesses institucionais e dos usuários.

Essa proposta fundamenta-se, portanto, na formação humanística aliada ao fazer técnico. Essa conjugação implica a reflexão teórica e visa à formação de profissionais críticos capazes de atuar no mercado de trabalho atual.

Os alunos poderão ainda cursar disciplinas optativas oferecidas no âmbito da ECI, da EBA ou cursar disciplinas em outros cursos da Universidade afins à sua formação, modalidade esta denominada de Formação Complementar. Tal perspectiva objetiva abrir a possibilidade de expandir a visão dos alunos sobre as interações que sua área de formação tem com outras profissões. Alguns cursos são centrais para a consolidação dessa área, tais como Conservação e Restauração de Bens Culturais Móveis, História, Artes Visuais, Turismo e Pedagogia, mas estão também no espectro de possibilidades do aluno cursar disciplinas e atividades acadêmicas das áreas de Ciências Biológicas, Geografia, Geologia, Administração, Ciências Sociais, Teatro, Design, Arquitetura e Educação.

O novo curso será constituído na modalidade de bacharelado, com quatro anos de duração, tal como os cursos de Biblioteconomia e Gestão da Informação e de Arquivologia. A estrutura curricular compreenderá a duração de oito semestres. As disciplinas do núcleo comum na presente proposta serão complementadas com disciplinas de um núcleo específico em Museologia e posteriormente, poderão ser complementadas com disciplinas optativas ou disciplinas complementares em outras unidades.

O curso está organizado para funcionamento em turno diurno e está previsto para se realizar em regime seriado semestral. A proposta curricular dos cursos de graduação da Escola de Ciência da Informação apresenta uma carga horária total de 2.400 h/a., sendo que 750 h./a. são destinadas às disciplinas do tronco comum em Ciência da Informação (que serão compartilhadas com o curso de Biblioteconomia e Gestão da 
Informação e com o de Arquivologia); 960 h./a. compõem o elenco de disciplinas específicas da Museologia (das quais 540 h./a. serão cursadas na Escola da Ciência da Informação e 420 h./a. na Escola de Belas Artes, envolvendo as questões de arte, exposição museográfica e conservação); 210h./a. destinadas à vivência profissional supervisionada; e 480 h./a. estão reservadas para que o aluno possa cursar disciplinas optativas (livres ou relacionadas a percursos pré-estabelecidos), e/ou formação complementar e/ou livre. Nessas 480 horas os alunos poderão também obter créditos por participação em atividades acadêmicas, tais como bolsas de iniciação científica, monitoria ou projetos de ensino, atividades de extensão, participação em eventos quando há apresentação de trabalhos e outras atividades previstas nas normas da UFMG sobre flexibilização curricular. As condições de créditos a serem atribuídos a essas atividades complementares (tempo mínimo de dedicação a estas atividades, quantidade de créditos a serem atribuídos, etc) serão posteriormente definidas por meio de resolução do colegiado do curso de Museologia.

Nos dois últimos semestres, o aluno do curso de Museologia realizará duas atividades de Vivência Profissional Supervisionada: Vivência Profissional Supervisionada A (70. período) e Vivência Profissional Supervisionada $\mathrm{B}\left(8^{\circ}\right.$. Período), que correspondem a uma carga horária total de 210 horas-aula. Além disso, ao longo do curso, os alunos terão carga horária livre para outras atividades acadêmicas, assim distribuídas: $90 \mathrm{~h} / \mathrm{a}$ no sexto período, $210 \mathrm{~h} / \mathrm{a}$ no sétimo e $180 \mathrm{~h} / \mathrm{a}$ no oitavo, totalizando $480 \mathrm{~h} / \mathrm{a}$. Esses horários são disponibilizados para que os alunos possam cursar disciplinas optativas do próprio curso de Museologia ou, então, disciplinas de formação complementar e/ou formação livre. As disciplinas optativas deverão ser oferecidas pelo curso de Museologia em quantidade suficiente para que os alunos que não se interessarem em cursar disciplinas em outras unidades como formação complementar ou livre possam integralizar parte das 2400 horas do curso na própria Escola de Ciência da Informação ou na unidade parceira, a Escola de Belas Artes.

No total, o conjunto de atividades acadêmicas obrigatórias (disciplinas, oficinas, atividades integrativas, estágios curriculares) perfaz 1920 horas, isto é, $80 \%$ do currículo, restando $20 \%$ da carga horária para atividades optativas. Entre as atividades obrigatórias, soma-se $1215 \mathrm{~h} / \mathrm{a}$ de carga horária teórica $(63,28 \%)$ e 705 h/a de carga horária prática $(36,72 \%)$.

Tal formato permite a realização de dois tipos de integralização para o curso. O primeiro é o caso do aluno que optar por integralizar seus créditos apenas com disciplinas do curso de Museologia e os créditos mínimos obrigatórios de Formação Livre. Neste caso, ele cumprirá 420 créditos com disciplinas ou atividades acadêmicas optativas previstas para o Núcleo Específico no currículo de Museologia, podendo, sob a orientação do Colegiado do Curso, percorrer por cinco áreas do conhecimento: 1) Museografia e Curadoria; 2) Gestão Documental em Museus; 3) Conhecimento Museal e Difusão Cultural; 4) Gestão em Museus e Espaços Culturais e 5) Gestão em Centros e Museus de Ciências. 
O segundo caso é o do aluno que optar tanto pela Formação Complementar quanto pela Livre. Neste caso, ele cumprirá no mínimo 20 créditos e no máximo 28 créditos na formação complementar, e ainda no mínimo quatro e o máximo 12 créditos na Formação Livre. Caso a soma dos créditos seja inferior a 32, ele cumprirá os demais créditos necessários para a integralização com atividades optativas do curso de Museologia, até o máximo de oito créditos (caso cumpra o mínimo previsto tanto na Formação Complementar quanto na Livre).

As disciplinas ou atividades de Formação Complementar previstas pelo curso de Museologia se referem à modalidade "aberta", isto é, não incluem uma lista pré-estabelecida. Ao contrário, incluem aquelas normalmente oferecidas pelas outras unidades da UFMG e serão escolhidas pelos alunos, que então solicitarão sua aprovação pela coordenação do curso de Museologia. A coordenação, contudo, irá se empenhar em, frequentemente, orientar e sugerir aos alunos disciplinas, cursos e áreas relevantes para ajudar na escolha, de acordo com os percursos pretendidos e com os seus interesses individuais.

\section{Considerações finais}

Os avanços contemporâneos na pesquisa e na produção de conhecimento em Ciência da Informação e em Museologia têm convergido nos últimos anos, o que parece demonstrar ser frutífera a união destas duas áreas. No entendimento da Escola de Ciência da Informação da UFMG, a Museologia tem muito a contribuir para a afirmação do caráter cultural e social da Ciência da Informação, numa potencialização das atividades desenvolvidas em Biblioteconomia e Arquivologia.

Por outro lado, a Ciência da Informação tem muito a fazer no sentido da afirmação científica da Museologia como campo de conhecimento, incorporando as questões colocadas pela realidade contemporânea, pelas possibilidades tecnológicas, pela priorização do acesso e dos usuários na prática profissional e na reflexão teórica e, por fim, no entendimento do museu e das práticas museais para além da especificidade de seus acervos e coleções (históricas, artísticas, científicas, comunitárias) em prol de um entendimento mais amplo, possibilitado pela operação do conceito de informação.

É essa a contribuição, para ambas as áreas, que a ECI/UFMG pretende promover no âmbito de sua reestruturação e ampliação dos cursos de graduação, processo este que ora se completa com o início das atividades acadêmicas do recém-criado curso de graduação em Museologia.

\section{Referências}

BORKO, H. Information Science: what is it? American Documentation, Washington, DC, v. 19, n. 1, p. .3-5, Jan. 1968. 
BUCKLAND, Michael K.; LIU, Ziming. History of Information Science. Annual Review of Information Science and Technology, Medford, NJ, v. 30, p. 385-416, 1995.

CALDEIRA, P. da T. Museus. In: CAMPELLO, B. S.; CALDEIERA, P. da T. Introdução às fontes de informação. Belo Horizonte: Autêntica, 2008. p. 141-157.

CÂNDIDO, Maria Inez. Documentação museológica. In: Caderno de diretrizes museológicas. Brasília: MinC/Iphan/Dept. de Museus e Centros Culturais; Belo Horizonte: Secretaria de Estado da Cultura/Superintendência de Museus, 2006.

CAPURRO, Rafael; HJORLAND, Birger. The concept of information. Annual Review of Information Science and Technology, Medford, NJ, v. 37, p. 343-411, 2003.

CAPURRO, Rafael. Epistemologia e ciência da informação. In: ENCONTRO NACIONAL DE PESQUISA EM CIÊNCIA DA INFORMAÇÃO, 5., 2003, Belo Horizonte. Anais... Belo Horizonte: Associação Nacional de Pesquisa e PósGraduação em Ciência da Informação e Biblioteconomia, 2003.

CARDOSO, Ana Maria Pereira. Informação e pós-modernidade: conceitos complementares? Perspectivas em Ciência da Informação. Belo Horizonte, v. 1, n. 1, p. 63-79, jan./jul. 1996.

CASTRO, Ana Lúcia Siaines de. Memórias clandestinas e sua museificação. Rio de Janeiro: Revan, 2007..

COLECIONISMO Mineiro. In SECRETARIA DE ESTADO DA CULTURA. Superintendência de Museus. Colecionismo Mineiro. Belo Horizonte: Associação dos Amigos do Museu Mineiro, 2002. p. 19-21.

CORNELIUS, Ian. Theorizing information for Information Science. .Annual Review of Information Science and Technology, Medford, NJ, v. 36, p. 393-425, 2002.

FERNÁNDEZ, Luis Afonso. Museología: introducción a La teoria y práctica del museo. Madrid: Istmo, 1993.

FROHMANN, Bernd. O caráter social, material e público da informação. In: FUJITA, M. S.; MARTELETO, R. M.; LARA, M. G. (Org.). A dimensão epistemológica da ciência da informação e suas interfaces técnicas, políticas e institucionais nos processos de produção, acesso e disseminação da informação. São Paulo: Cultura Acadêmica; Marília: Fundepe, 2008.

GOMES, Henriette. Interdisciplinaridade e Ciência da Informação: de característica a critério delineador de seu núcleo principal. DataGramaZero - Revista de Ciência da Informação, v. 2, n. 4, ago. 2001. GONZÁLEZ DE GÓMEZ, Maria Nélida. Metodologia de pesquisa no campo da Ciência da Informação. DataGramaZero - Revista de Ciência da Informação, v.1, n.6, dez. 2000. 
HERNÁNDEZ HERNÁNDEZ, Francisca. Manual de museología. Madrid: Síntesis, 1998.

HJORLAND, Birger. Epistemology and the socio-cognitive perspectives in Information Science. JASIS, New York, NY, v..53, n. 4, p. 257-270, 2002.

JULIÃO, Letícia. Apontamentos sobre a história do museu. In: Caderno de Diretrizes Museológicas. Brasília: MinC/Iphan/Departamento de Museus e Centros Culturais; Belo Horizonte: Secretaria de Estado da Cultura/Superintendência de Museus, 2006, p. 19-31.

MAGALHÃES, F. Apresentação. In: FUNDAÇÃO NACIONAL DE ARTE. Pinacoteca do Estado. Pinacoteca do Estado - São Paulo. Rio de Janeiro: Secretaria de Cultura do Estado de São Paulo, 1982. 204p. Il. (Museus brasileiros, 6).

MENESES, U. T. B. de. A exposição museológica e o conhecimento histórico. In: FIGUEIREDO, B. G.; VIDAL, D. G. Museus: dos gabinetes de curiosidades ao museu moderno. Belo Horizonte: Argvmentvm; Brasília, DF: CNPq, 2005.

MIKSA, Francis. Library and information science: two paradigms. In: VAKKARI, Perti; CRONIN, Blaise (Ed.). Conceptions of library and information science: historical, empirical and theoretical perspectives. London: Taylor Graham, 1992. p. 229-252.

NASCIMENTO JR., José; CHAGAS, Mário. Museu e política: apontamentos de uma cartografia. In: Caderno de Diretrizes Museológicas. Brasília: MinC/Iphan/Departamento de Museus e Centros Culturais; Belo Horizonte: Secretaria de Estado da Cultura/Superintendência de Museus, 2006. p. 13-17.

ORTEGA, Cristina. Relações históricas entre Biblioteconomia, Documentação e Ciência da Informação. DataGramaZero - Revista de Ciência da Informação, v. 5, n. .5, out. 2004.

PEREIRA, J. S. et al. Escola e museu: diálogos e práticas. Belo Horizonte: Secretaria de Estado da Cultura Superintendência de Museus, 2007. p. 11.

PIMENTEL, T. V. C.; COSTA, T. C. Monografias tridimensionais: exposições da média e curta duração do Museu Histórico Abílio Barreto. In: Cadernos de diretrizes museológicas 2. Belo Horizonte: Superintendência de Museus, 2008. p. 127-143.

PINHEIRO, Lena Vânia Pinheiro; LOUREIRO, José Matheus. Traçados e limites da ciência da informação. Ciência da Informação, Brasília, v. 24, n. 1, p. 42-53, jan./abr. 1995.

PINHEIRO, Lena Vânia Ribeiro. Gênese da Ciência da Informação ou sinais anunciadores da nova área. In: AQUINO, Mirian de Albuquerque (Org.). $O$ campo da Ciência da Informação: gênese, conexões e especificidade. João Pessoa: Ed. Universitária UFPB, 2002. p. 61-86. 
RENDÓN ROJAS, Miguel. Relación entre los conceptos: información, conocimiento y valor. Semejanzas y diferencias. Ciência da Informação, Brasília, v. 34, n. 2, p. 52-61, maio/ago. 2005.

ROBREDO, Jaime. Da ciência da informação revisitada aos sistemas humanos de informação. Brasília: Thesaurus, 2003.

SCHEINDER, Tereza Cristina. O museu como processo. In: Caderno de diretrizes museológicas. Belo Horizonte: Superintendência de Museus, 2008.

SANTOS, M. C. T. M. Museu e educação: conceitos e métodos. Ciências \& Letras, Porto Alegre, n. 312, p. 307-323, jan./jun. 2002.

SARACEVIC, Tefko. Ciência da informação: origem, evolução e relações. Perspectivas em Ciência da Informação. Belo Horizonte, v.1, n.1, p. 4162, jan./jun. 1996.

SILVA, Armando Malheiro. Arquivística, Biblioteconomia e Museologia: do empirismo patrimonialista ao paradigma emergente da CI. In: Integrar 10 Congresso Internacional de Arquivos, Bibliotecas, Centros de Documentação e Museus. São Paulo: FEBAB, 2002, p.573-607.

SMIT, Johanna. Arquivologia, biblioteconomia e museologia - o que agrega estas atividades profissionais e o que as separa? Revista Brasileira de Biblioteconomia e Documentação. São Paulo, Nova Série, v. 1, n. 2, p. 27-36, fev. 2002.

WERSIG, Gernot. Information science: the study of postmodern knowledge usage. Information processing \& management, Elmsford, NJ, v. 29, n. 2, p. 229-239, Mar. 1993.

\section{ANEXO - Grade curricular do curso de Museologia}

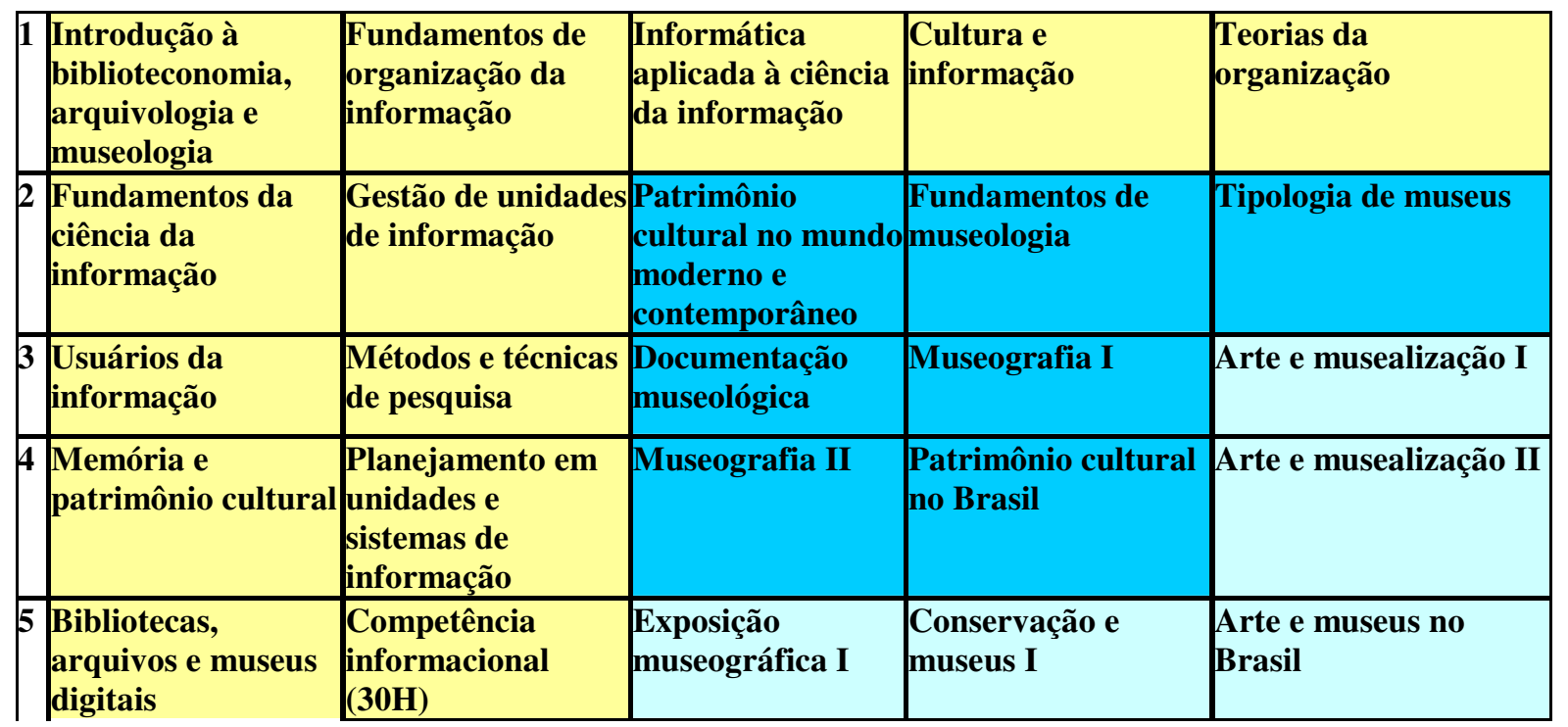




\begin{tabular}{|c|c|c|c|c|c|}
\hline & & $\begin{array}{l}\text { Função social dos } \\
\text { museus (30H) }\end{array}$ & & & \\
\hline 6 & $\begin{array}{l}\text { Metodologia da } \\
\text { pesquisa histórica } \\
\text { em museus }\end{array}$ & $\begin{array}{l}\text { Patrimônio } \\
\text { cultural mineiro } \\
(30 \mathrm{H})\end{array}$ & $\begin{array}{l}\text { Exposição } \\
\text { museográfica II }\end{array}$ & $\begin{array}{l}\text { Conservação e } \\
\text { museus II }\end{array}$ & $\begin{array}{l}\text { Outras atividades } \\
\text { acadêmicas }(90 \mathrm{H})\end{array}$ \\
\hline 7 & $\begin{array}{l}\text { Vivência } \\
\text { profissional } \\
\text { supervisionada em } \\
\text { museologia A } \\
(90 \mathrm{H})\end{array}$ & $\begin{array}{l}\text { Outras atividades } \\
\text { acadêmicas }\end{array}$ & $\begin{array}{l}\text { Outras atividades } \\
\text { acadêmicas }\end{array}$ & $\begin{array}{l}\text { Outras atividades } \\
\text { acadêmicas }\end{array}$ & $\begin{array}{l}\text { Outras atividades } \\
\text { acadêmicas } \\
(30 \mathrm{H})\end{array}$ \\
\hline 8 & $\begin{array}{l}\text { Vivência } \\
\text { profissional } \\
\text { supervisionada em } \\
\text { museologia B } \\
(120 \text { H) }\end{array}$ & $\begin{array}{l}\text { Outras atividades } \\
\text { acadêmicas }\end{array}$ & $\begin{array}{l}\text { Outras atividades } \\
\text { acadêmicas }\end{array}$ & $\begin{array}{l}\text { Outras atividades } \\
\text { acadêmicas } \\
(30 H)\end{array}$ & $\begin{array}{l}\text { Outras atividades } \\
\text { acadêmicas } \\
(30 \mathrm{H})\end{array}$ \\
\hline
\end{tabular}

Observações:

1. A cor amarela representa disciplina pertencentes ao Tronco Comum de Ciência da Informação. O azul escuro representa as disciplinas do Tronco Específico de Museologia a serem ministradas na Escola de Ciência da Informação. O azul claro representa as disciplinas do Tronco Específico de Museologia a serem ministradas na Escola de Belas Artes.

2. Todas as atividades perfazem uma carga horária de 60 horas/aula, exceto aquelas cuja carga horária é discriminada logo após o nome da atividade. 